\title{
A COMPARATIVE STUDY OF ONDANSETRON AND GRANISETRON IN THE PREVENTION OF POST- OPERATIVE NAUSEA AND VOMITING (PONV) IN DAY-CARE SURGERY
}

\author{
V. Sumithra Kumar1, R. Remadevi², N. Pratheeba ${ }^{3}$ \\ ${ }^{1}$ Chief Medical Officer, Department of Anaesthesiology, Rajiv Gandhi Women and Children Hospital, Pondicherry. \\ ${ }^{2}$ Assistant Professor, Department of Anaesthesiology, IGMC \& RI, Pondicherry. \\ ${ }^{3}$ Associate Professor, Department of Anaesthesiology, IGMC \& RI, Pondicherry.
}

ABSTRACT
CONTEXT
A major factor behind this Day-Care surgery has been substantial savings in medical costs apart from increasing the convenience
to the patient. From an anaesthetic viewpoint, one of the primary goals with respect to outpatient anaesthesia is prompt recovery
with minimal side effects and quick discharge.

AIMS

To compare the efficacy and side effects of ondansetron and granisetron in the prevention of Postoperative Nausea and Vomiting (PONV) in female patients of reproductive age group undergoing Day-Care surgery.

\section{SETTINGS AND DESIGN}

Randomised double blind.

\section{METHODS AND MATERIAL}

150 female patients, ASA I and II, between the age of 18-45 yrs. undergoing Day-Care surgery. The patients were randomly allocated to one of the three groups (50 in each group). Group C ( $\mathrm{n}=50)$ : Control group. Received normal saline $2 \mathrm{~mL}$ intravenously. Group G ( $n=50)$ : Granisetron group received Inj. Granisetron $1 \mathrm{mg} I V$ made to $2 \mathrm{~mL}$ with normal saline. Group O ( $n=50)$ : Ondansetron group. Received Inj. Ondansetron $4 \mathrm{mg}$ IV in $2 \mathrm{~mL}$. Incidence of PONV was studied during two periods after surgery in the PACU (0$2 \mathrm{hrs}$.) and in the ward (2-6 hrs.). Patients were asked to rate nausea on a four-point scale as 0 - none, 1 - mild, 2 - moderate or 3 severe. A telephonic interview was held with the patient 24 hours after surgery. This assessed the incidence of retching/vomiting, the incidence and severity of nausea and pain during the 24 hours after discharge.

\section{STATISTICAL ANALYSIS}

ANOVA, Chi-square, Fisher's Exact test was done.

\section{RESULTS}

9 patients (18\%) in the placebo group suffered from vomiting, whereas only $6(12 \%)$ in the ondansetron group and $3(6 \%)$ in the granisetron group were affected. The incidence of PONV without prophylaxis was $20 \%$ with Group G (Inj. granisetron) was $10 \%$ and Group 0 (Inj. ondansetron) was 16\%. This difference was not statistically significant in the 2-6 hours' period, Group G (Inj. granisetron) was found to be more effective than Group C (placebo) $(\mathrm{p}<0.05)$ in preventing vomiting. In the post discharge period (6-24 hrs.), Group G (Inj. granisetron) was more effective than Group C (placebo) (p <0.005) and Group 0 (Inj. ondansetron) $(\mathrm{p}<0.05)$ in the prevention of PONV.

\section{CONCLUSION}

We conclude either granisetron and ondansetron is equally effective for the control of PONV in the first 6 hours after Day-Care surgery, granisetron is more effective than ondansetron in the post-discharge period.

\section{KEYWORDS}

5-HT3 Antagonists, Granisetron, Ondansetron, Day-Care Surgery, Post-Operative Nausea and Vomiting.

HOW TO CITE THIS ARTICLE: Kumar VS, Remadevi R, Pratheeba N. A comparative study of ondansetron and granisetron in the prevention of post-operative nausea and vomiting (PONV) in day-care surgery. J. Evolution Med. Dent. Sci. 2016;5(69):4989-4994, DOI: $10.14260 /$ jemds/2016/1133

\section{INTRODUCTION}

It is a well-known fact that the number of surgeries performed on a day-care basis is on the increase. A major factor behind this growth has been substantial savings in medical costs apart from increasing the convenience to the patient. [1]

Financial or Other, Competing Interest: None.

Submission 07-08-2016, Peer Review 20-08-2016,

Acceptance 22-08-2016, Published 27-08-2016.

Corresponding Author:

Dr. R. Remadevi,

Type- $V-A / 13$,

Jipmer Campus,

Pondicherry.

E-mail: remadevi70@gmail.com

DOI: $10.14260 / \mathrm{jemds} / 2016 / 1133$
From an anaesthetic viewpoint one of the primary goals with respect to outpatient anaesthesia is prompt recovery with minimal side effects and quick discharge. Subsequently, Postoperative Nausea and Vomiting (PONV), appropriately called "the big little problem[2]" of ambulatory surgery has become a serious issue in the outpatient setting. This is due to its potential to partially or completely negate the savings in medical costs, increase the expenses for treatment of PONV and decrease patient satisfaction. Thus, a key objective of the providers of day-care anaesthesia has been the prevention of PONV. Similarly, the objective of this investigation was the study of prevention of PONV in female patients, who are at a 
higher risk of PONV with a specific focus on the newest class of antiemetics, the serotonin antagonists.

Serotonin antagonists were developed through modifications in the antiemetic metoclopramide, and work by selectively blocking the serotonin receptors both centrally - in the hypothalamus, the chemoreceptor trigger zone and the cerebral cortex and peripherally in the enterochromaffin cells of the intestinal mucosa. Ondansetron was the first drug in this group to be introduced in 1991.[3,4] Granisetron was introduced in 1993 and was initially used only for prevention of chemotherapy-induced nausea and vomiting.[5] Its use for PONV was approved by the FDA only in 2002.

While there are a number of studies comparing ondansetron with conventional antiemetics for PONV, there are a smaller number of studies comparing granisetron with other antiemetics and even fewer comparing the two serotonin antagonists (ondansetron and granisetron) to one another.

Hence, this study was designed to differentiate the efficacy of ondansetron and granisetron in the prevention of PONV in female patients undergoing day-care surgery.

\section{AIM}

To compare the efficacy and side effects of ondansetron and granisetron in the prevention of Postoperative Nausea and Vomiting (PONV) in female patients of reproductive age group undergoing day-care surgery.

\section{MATERIAL AND METHODS}

150 female patients between the age of 18 to 45 yrs., belonging to ASA I and II classes who gave informed consent for undergoing day-care surgery with duration less than 45 mins, general surgery like breast lump excision, sebaceous cyst excision, wound debridement, lymph node biopsy and Gynaecological surgeries like diagnostic hysteroscopy, diagnostic laparoscopy, interval sterilisation, laparoscopic myomectomy, laparoscopic ovarian cyst excision, Medical Termination of Pregnancy (MTP), MTP with sterilisation were included into the study after getting the Institutional Ethical Committee approval. The following patients were excluded from the study, history of reaction to ondansetron, granisetron or metoclopramide, any previous history of PONV, patients with gastro-intestinal disease or pre-existing nausea or vomiting, patients who had taken antiemetics within 24 hours of surgery, pregnant or lactating mothers, patients not willing to take part in the study. No premedication was given to any of these patients. On arrival in the operating room, after starting an intravenous cannula and infusion, routine monitoring devices were attached and baseline blood pressure, heart rate and oxygen saturation were recorded.

The medications were prepared in equivalent volumes $(2$ $\mathrm{mL}$ ) by an assistant. Both the patient and the observer were blinded to the nature of the medication administered. The prepared medication was administered intravenously over one minute before induction.

Anaesthesia was induced with fentanyl $1.0-1.5 \mu \mathrm{g} \mathrm{kg}^{-1} \mathrm{IV}$ followed by propofol $2.0-2.5 \mathrm{mg} \mathrm{kg}^{-1}$ IV. The airway was maintained using a facemask or LMA (Laryngeal Mask Airway). The airway was handled by expert anaesthesiologist, spontaneous respiration was maintained and gentle assisted ventilation in case the respiration becomes shallow care was taken not to distend the abdomen during mask ventilation.
Anaesthesia was maintained with isoflurane $1 \%-1.5 \%$ in a mixture of nitrous oxide and oxygen in the ratio of 2:1. The anaesthetic agent was adjusted with the goal of maintaining blood pressure within $20 \%$ of pre-induction value. Diclofenac suppository $50 \mathrm{mg}$ was inserted after induction of anaesthesia prior to the start of surgery. All the patients received oxygen 5 litre per minute by face mask for one hour after the procedure was over.

Blood pressure, heart rate and $\mathrm{SpO}_{2}$ were monitored every minute for the first 10 mins and every 5 mins subsequently till the end of surgery, every 15 mins for $2 \mathrm{hrs}$. after surgery in the PACU. Thereafter, the blood pressure and heart rate were monitored hourly in the ward till discharge. The nature and duration of surgery was recorded. Recovery time, i.e. the time taken to respond to verbal command was also noted. The patients were monitored in the PACU for 2 hours and shifted to the ward. They were discharged from the hospital when they were able to walk comfortably and take oral fluids.

Incidence of PONV was studied during two periods after surgery in the PACU for 2 hrs. and in the ward 2 to $6 \mathrm{hrs}$. The assessments were made at the end of each period. Patients were asked to rate nausea on a four-point scale as 0 - none, 1 mild, 2 - moderate or 3 - severe. Retching and vomiting were assigned together under the common category - emetic episode and assessed as present or absent.

If the patient had a nausea score of $\geq 2$ for more than one hour or $\geq 2$ emetic episodes they were treated with $10 \mathrm{mg}$ metoclopramide IV. If the initial "rescue" antiemetic was inefficient, promethazine $12.5 \mathrm{mg}$ IV was administered. Pain intensity was also rated on the verbal response score and the presence of other side effects were also noted.

A telephonic interview was held with the patient 24 hours after surgery. This assessed the incidence of retching/vomiting, the incidence and severity of nausea and pain during the 24 hours after discharge.

\section{Statistical Analysis}

The age, height, weight and BMI in the three groups are compared and analysed using ANOVA. The distribution of facemask versus laryngeal mask, and the ASA grading in the three groups, was analysed by chi-square test and there was no statistically significant difference between the three groups. The duration of surgery and the time to recovery after cutting off of the anaesthetic agent was also studied and analysed by ANOVA. In the third time frame, there was no incidence of PONV in the Granisetron group. With a value of zero, Chi-square test was not applicable and hence Fisher's exact test was done. Granisetron was found to be more effective than placebo in this period with a $\mathrm{P}$ value of $<0.005$, and more effective than ondansetron with a $P$ value of $<0.05$. A P value of $<0.05$ was considered statistically significant. SPSS for Windows, Version 11.0. Chicago, SPSS Inc. was used.

\section{RESULTS}

The three groups in the study were comparable in terms of age, weight and body mass index (Table 1). The method of induction and maintenance of anaesthesia was uniform. Airway was maintained with either a facemask or a laryngeal mask and there was no significant difference in the distribution of the two among the groups (Table 2). Duration of surgery and recovery time (Table 3). Type of Surgery in each Groups (Table 4). Incidence of PONV (Table 5). In the third 
time frame, there was no incidence of PONV in the Granisetron group. With a value of zero, Chi-square test was not applicable and hence Fisher's exact test was done. Granisetron was found to be more effective than placebo in this period with a $\mathrm{P}$ value of $<0.005$, and more effective than ondansetron with a $P$ value of $<0.05$.

(Table 6) The incidence of PONV without prophylaxis was $20 \%$ with Group G (Inj. granisetron) was $10 \%$ and Group 0 (Inj. ondansetron) was $16 \%$. This difference was not statistically significant in the immediate postoperative period; there was no statistically significant difference between the three groups. In the 2-6 hours' period Group G (Inj. granisetron) was found to be more effective than Group C (placebo) $(\mathrm{p}<0.05)$ in preventing vomiting. In the post discharge period (6-24 hrs.) Group G (Inj. granisetron) was more effective than Group C (placebo) $(\mathrm{p}<0.005)$ and Group 0 (Inj. ondansetron) $(\mathrm{p}<0.05)$ in the prevention of PONV. Use of Rescue Antiemetic (Table 9). Headache and giddiness were the main side effects seen during the study. Two patients, both belonging to the placebo group had to stay in the hospital overnight, as they were not able to tolerate oral feeding.

\begin{tabular}{|c|c|c|c|c|}
\hline 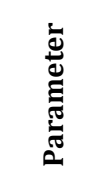 & 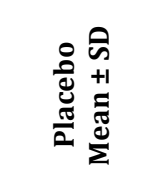 & 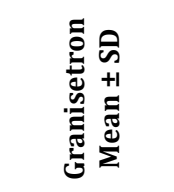 & 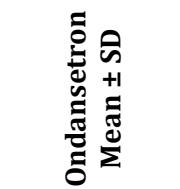 & 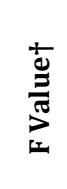 \\
\hline Age & $31.24 \pm 6.67$ & $30.66 \pm 5.88$ & $30.30 \pm 6.21$ & .296 \\
\hline Weight & $58.94 \pm 8.86$ & $59.70 \pm 10.88$ & $58.44 \pm 10.37$ & .198 \\
\hline Height & $1.53 \pm 0.058$ & $1.52 \pm 0.093$ & $1.53 \pm 0.069$ & .382 \\
\hline BMI & $25.02 \pm 3.64$ & $25.82 \pm 4.93$ & $24.80 \pm 4.21$ & .782 \\
\hline
\end{tabular}

BMI (Body Mass Index), SD Standard deviation, †ANOVA result is reported as an $F$-value

\begin{tabular}{|c|c|c|c|c|}
\hline & Placebo & Granisetron & Ondansetron & $\mathbf{X 2}^{*}$ \\
\hline $\begin{array}{c}\text { ASA } \\
\text { Gr I }\end{array}$ & 42 & 46 & 45 & 1.72 \\
\hline $\begin{array}{c}\text { ASA } \\
\text { Gr II }\end{array}$ & 8 & 4 & 5 & 1.72 \\
\hline $\begin{array}{c}\text { GA/ } \\
\text { MASK }\end{array}$ & 20 & 24 & 27 & 1.98 \\
\hline GA/LMA & 30 & 26 & 23 & 1.98 \\
\hline \multicolumn{4}{|c|}{ Table 2: ASA Grade \& Type of Anaesthesia } \\
\hline
\end{tabular}

ASA (American Society of Anaesthesiologist), LMA (Laryngeal Mask Airway), GA (General Anaesthesia) * $\mathrm{X}^{2}$ chi-squared test statistic

\begin{tabular}{|c|c|c|c|c|}
\hline 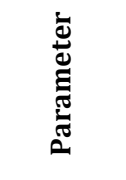 & 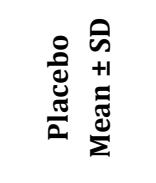 & 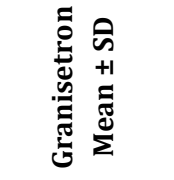 & 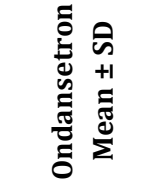 & 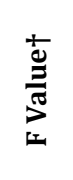 \\
\hline $\begin{array}{l}\text { Duration } \\
\text { of } \\
\text { Surgery } \\
\text { (min.) }\end{array}$ & $30.40 \pm 11.5$ & $28.60 \pm 13.32$ & $28.90 \pm 13.02$ & .291 \\
\hline $\begin{array}{c}\text { Recovery } \\
\text { Time } \\
\text { (min.) }\end{array}$ & $5.34 \pm 1.89$ & $5.26 \pm 1.88$ & $5.04 \pm 1.62$ & .370 \\
\hline
\end{tabular}

$\mathrm{SD}=$ Standard Deviation, $\uparrow$ ANOVA result is reported as an $F$-value

\begin{tabular}{|c|c|c|c|c|}
\hline Surgery & $\begin{array}{c}\text { Prophylactic } \\
\text { Placebo }\end{array}$ & $\begin{array}{l}\text { Antiemetic } \\
\text { Granisetron }\end{array}$ & Ondansetron & Total \\
\hline Breast lump excision & 9 & 11 & 5 & 25 \\
\hline Dilatation \& Curettage dilatation \& & 8 & 9 & 11 & 28 \\
\hline Evacuation & 2 & 0 & 0 & 2 \\
\hline Diag. hysterolaparoscopy & 5 & 7 & 6 & 18 \\
\hline Diag. laparoscopy & 2 & 1 & 4 & 7 \\
\hline Ganglion removal & 0 & 0 & 1 & 1 \\
\hline Hysteroscopic polypectomy & 1 & 0 & 0 & 1 \\
\hline Hysteroscopy & 5 & 4 & 6 & 15 \\
\hline Incision \& drainage & 1 & 1 & 0 & 2 \\
\hline Interval sterilisation & 1 & 1 & 1 & 3 \\
\hline Lap. Myomectomy & 1 & 0 & 1 & 2 \\
\hline Lap. Ovarian Cystectomy & 1 & 1 & 0 & 2 \\
\hline Lap. Sterilisation & 2 & 2 & 3 & 7 \\
\hline Lateral Sphincterotomy & 2 & 0 & 0 & 2 \\
\hline Lymph node biopsy & 0 & 2 & 2 & 4 \\
\hline MTP* & 3 & 7 & 6 & 16 \\
\hline MTP*, Lap sterilisation & 5 & 3 & 3 & 11 \\
\hline Sebaceous cyst excision & 1 & 1 & 0 & 2 \\
\hline Wound debridement & 1 & 0 & 1 & 2 \\
\hline Total & 50 & 50 & 50 & 150 \\
\hline
\end{tabular}

*MTP Medical Termination of Pregnancy 


\begin{tabular}{|c|c|c|c|c|}
\hline PONV & Placebo & Granisetron & Ondansetron & $\chi^{2^{*}}$ \\
\hline $\begin{array}{c}0-24 \\
\text { Hrs. }\end{array}$ & 10 & 5 & 8 & 1.72 \\
\hline $\begin{array}{c}0-2 \\
\text { Hrs. }\end{array}$ & 7 & 3 & 2 & 2.70 \\
\hline $\begin{array}{c}2-6 \\
\text { Hrs. }\end{array}$ & 7 & 3 & 3 & 2.70 \\
\hline $\begin{array}{c}\text { - } 24 \\
\text { Hrs. }\end{array}$ & 8 & 0 & 5 & \\
\hline \multicolumn{5}{|c|}{ Table 5: Incidence of PONV } \\
\hline
\end{tabular}

* $\mathrm{X}^{2}$ Chi-Squared Test Statistic

\begin{tabular}{|c|c|c|c|c|}
\hline Nausea & $\begin{array}{c}\text { Placebo } \\
\text { (n) }\end{array}$ & $\begin{array}{c}\text { Granisetron } \\
\text { (n) }\end{array}$ & $\begin{array}{c}\text { Ondansetron } \\
\text { (n) }\end{array}$ & $\begin{array}{c}\text { F } \\
\text { Value } \dagger\end{array}$ \\
\hline $\begin{array}{c}0-24 \\
\text { Hrs. }\end{array}$ & 10 & 5 & 7 & 1.981 \\
\hline $\begin{array}{c}0-2 \\
\text { Hrs. }\end{array}$ & 7 & 3 & 2 & 1.691 \\
\hline $\begin{array}{c}2-6 \\
\text { Hrs. }\end{array}$ & 7 & 3 & 2 & 2.049 \\
\hline $\begin{array}{c}6-24 \\
\text { Hrs. }\end{array}$ & 7 & 0 & 5 & $3.166^{*}$ \\
\hline \multicolumn{5}{|r}{ Table 6: Incidence of Nausea in the Three Groups } \\
\hline
\end{tabular}

†ANOVA result is reported as an F-value, ${ }^{*} \mathrm{p}<.05$

\begin{tabular}{|c|c|c|c|c|}
\hline 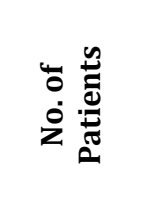 & $\begin{array}{l}0 \\
\frac{0}{0} \\
\frac{\pi}{2} \\
1\end{array}$ & 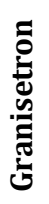 & 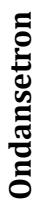 & 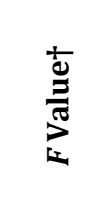 \\
\hline $\begin{array}{c}\text { E.E in } 24 \\
\text { Hrs. }\end{array}$ & 9 & 3 & 6 & 1.016 \\
\hline $\begin{array}{c}\text { E.E } 0-2 \\
\text { Hrs. }\end{array}$ & 5 & 3 & 2 & 0.888 \\
\hline $\begin{array}{c}\text { E.E } 2-6 \\
\text { Hrs. }\end{array}$ & 7 & 0 & 2 & $4.855^{*}$ \\
\hline $\begin{array}{c}\text { E.E } 6-24 \\
\text { Hrs. }\end{array}$ & 3 & 0 & 3 & 1.499 \\
\hline
\end{tabular}

E.E - Emetic Episodes, †ANOVA result is reported as an $F$ value, ${ }^{*} \mathrm{p}<0.05$.

\begin{tabular}{|c|c|c|c|}
\hline $\begin{array}{c}\text { Frequency } \\
\text { of E.E }\end{array}$ & Placebo & Granisetron & Ondansetron \\
\hline In 24 Hrs. & 29 & 6 & 11 \\
\hline $0-2 \mathrm{Hrs}$. & 12 & 6 & 4 \\
\hline $2-6 \mathrm{Hrs}$. & 14 & 0 & 3 \\
\hline 6-24 Hrs. & 3 & 0 & 4 \\
\hline \multicolumn{3}{|c|}{ Table 8: Frequency of Emetic Episodes } \\
in the Three Groups \\
\hline
\end{tabular}

E.E - Emetic Episodes

\begin{tabular}{|c|c|c|c|c|}
\hline & & 0 & 0 \\
\hline
\end{tabular}

${ }^{*} \mathrm{X}^{2}$ chi-squared test statistic

*Fisher's test value

\section{DISCUSSION}

Post-operative nausea and vomiting continues to be the bane of day-care surgery despite the numerous modalities available for the prophylaxis and treatment of the same. In fact, the controversy whether prophylaxis or treatment is more cost effective in the management of PONV is yet to be settled. The search for an ideal agent for the prophylaxis of PONV is still on.

The three groups in the study were comparable in terms of age, weight and body mass index. The method of induction and maintenance of anaesthesia was uniform. Airway was maintained with either a facemask or a laryngeal mask and there was no significant difference in the distribution of the two among the groups. In addition, there were no significant differences in the duration of surgery or recovery time in the three groups. A relationship between PONV and airway management was demonstrated by L. Doubravska[6] was highest after orotracheal intubation (18.8\%), but lower with face mask $(8.9 \%)$ or laryngeal mask (6.2\%) placement. Kovac $\mathrm{AL}^{[7]}$ and Gan $\mathrm{TJ}^{[8]}$ observed that certain surgical like abdominal, laparoscopic, ophthalmic, gynaecological, neurological, plastic and aesthetic or middle ear surgery and strumectomy and anaesthetic management influencing PONV include premedication, type of anaesthesia, induction agents used, opioids, nasogastric suction, muscle relaxation reversal, anaesthesiologist's experience, etc.

Of the 50 patients who did not receive any prophylaxis for PONV, 10 patients suffered from nausea or vomiting at some point over the study period. Hence, there was a $20 \%$ incidence of PONV without prophylaxis in this study group. Watcha MF and White $\mathrm{PF}^{[9]}$ have associated general anaesthesia with volatile agents to be associated with a $20-30 \%$ incidence of PONV, which corresponds to the results of our study. But this incidence was found to vary depending on a number of factors. However, let us consider the risk scores developed by Apfel et al[10] where a score is developed from 4 predictors: female gender, history of motion sickness, non-smoking status and use of postoperative opioids. If none, one, two, three or four predictors were present, the incidences of PONV were 10, 21, 39,61 and $70 \%$ respectively. In this study population, two risk factors namely female gender and non-smoking status were present and so the expected incidence of PONV would be around 39\%. But the actual incidence was only $20 \%$. This could probably be due to the use of propofol with known antiemetic effects for induction and Inj. Fentanyl, which causes less emesis than the opioids in use earlier.

A complete response in terms of absence of PONV within 2 hours after surgery was seen in $86 \%$ of patients who received placebo as against $96 \%$ in the Ondansetron group and $94 \%$ in the Granisetron group. This same trend continued in the 2-6 hours' period. The corresponding values in the 6-24 hours' period were $84 \%, 90 \%$ and $100 \%$.

While there is an appreciable reduction in the incidence of PONV when antiemetic prophylaxis is used, the results did not reach statistical significance except in the 6-24 hours' period when granisetron was found to be more effective than placebo and ondansetron in controlling PONV. However, when the entire 24-hour period was considered, the incidence of PONV was $20 \%$ in the Placebo group, $10 \%$ in the Granisetron group and $18 \%$ in the Ondansetron group.

Almost all the studies comparing ondansetron and granisetron for the prophylaxis of PONV like those by Naguib 
M et al[11] Gan TJ et al[12] and White PF et al[13] did not find any difference between the two 5-HT3 receptor antagonists.

This was in contrast to the better efficacy of granisetron in the prevention of chemotherapy-induced nausea and vomiting, which was proven in a number of studies like those by Specter JI et al[14] Carmichael et al[15] and De Wit et al.[16] So also in our study there was no significant advantage of one 5HT3 receptor blocker over the other for the prevention of PONV over 24 hours.

It is evident that the severity of nausea was more in the placebo group compared to the other two groups. While three patients in the placebo group continued to experience nausea over 24 hours despite treatment, no such complaints were seen in the groups receiving prophylaxis.

The number of patients who suffered from emetic episodes was 9 in the placebo group as compared to 7 in the ondansetron group and 3 in the granisetron group. While this difference does not seem to be much, when a comparison of the number of emetic episodes in each group is made the gap is wider. There were 29 episodes in the Placebo group, 11 in the Ondansetron group and 6 in the Granisetron group and this difference was significant showing that both the 5-HT3 receptor blockers reduced the severity of vomiting in the postoperative period.

A finding of possible significance was that 4 patients in the ondansetron group developed PONV only in the post discharge period. One of these patients also resorted to a single dose of oral ondansetron $4 \mathrm{mg}$, 9 hours after surgery and her symptoms were effectively controlled.

Hartsell T et al[17] studied the efficacy of oral ondansetron versus placebo given postoperatively in patients who underwent surgery for acoustic neuroma. They found that ondansetron $8 \mathrm{mg}$ b.i.d. for two days postoperatively was better than placebo. This also raises the question whether in our study the use of an oral dose of ondansetron in the postoperative period would have prevented PONV in these 4 patients. Bhattacharya D et al[18] compared the efficacy of ondansetron and granisetron for prevention of PONV after day care gynaecological laparoscopy in a double-blind randomised placebo controlled trial. They found that incidences of emetic episodes were $20 \%$ in ondansetron group and $7 \%$ in granisetron group, which is clinically significant $(\mathrm{P}<0.05)$.

The difference seen between ondansetron and granisetron in the post-discharge period could be due to the more prolonged action of the latter. Moreover, the difference between the two drugs was statistically significant in the postdischarge period proving that granisetron could be a better drug for control of post-discharge nausea and vomiting in daycare surgery.

While 7 patients in the Placebo group needed treatment with inj. metoclopramide $10 \mathrm{mg}$, only 4 patients needed rescue antiemetic in each of the other two groups. What was more significant was the fact that while there was complete response in the groups which received prophylaxis, 4 patients needed another antiemetic in the form of inj. promethazine 25 mg. Hence, the use of prophylaxis with granisetron or ondansetron reduced the need for rescue antiemetics and also allowed for better response to the treatment of PONV if it occurred.

The side effects commonly associated with the use of 5HT3 receptor antagonists are headache, diarrhoea and constipation. In this study 5 patients in the Ondansetron group, 2 patients each in the Granisetron group and Placebo group had headache. The pain was mild in most of the patients. Only 2 patients in the Ondansetron group had moderate pain, which necessitated treatment with Tab. Paracetamol $650 \mathrm{mg}$. There were no complaints of diarrhoea or constipation in any patient.

The other problem which was encountered was giddiness, which occurred in 2 patients in the Placebo group. Since both these patients had also received Inj. promethazine for PONV, the giddiness was probably due to this.

5-HT3 receptors have also been proven to cause QTC prolongation. However, no significant arrhythmia was noted in any of the patients during the intraoperative period or during the 0-2 hours' recovery period in the PACU.

Two of the patients in the placebo group who were otherwise planned for day-care surgery had to be admitted to the hospital overnight, as they were not able to tolerate oral feeds. While this difference was not statistically significant, no such untoward result was seen in any of the patients who received PONV prophylaxis with either ondansetron or granisetron.

\section{CONCLUSION}

We conclude either granisetron and ondansetron is equally effective for the control of PONV in the first 6 hours after daycare surgery, granisetron is more effective than ondansetron in the post-discharge period. Hence, granisetron will be a better choice for prophylaxis of PONV.

\section{REFERENCES}

1. Watcha MF. The cost-effective management of postoperative nausea and vomiting. Anesthesiology 2000;92(4):931-3.

2. Kapur PA. The big little problem. Anesth Analg 1991;73(3):243-5.

3. Larijani GE, Gratz I, Afshar M, et al. Treatment of postoperative nausea and vomiting with ondansetron: a randomized, double-blind comparison with placebo. Anesth Analg 1991;73(3):246-9.

4. Tyers MB, Bunce KT, Humphrey PP. Pharmacological and anti-emetic properties of ondansetron. Eur J Cancer Clin Oncol 1989;25(Suppl 1):S15-9.

5. Mikawa K, Takao Y, Nishina K, et al. The antiemetic efficacy of prophylactic granisetron in gynecologic surgery. Anesth Analg 1995;80(5):970-4.

6. Doubravska L, Dostalova K, Fritscherova S, et al. Incidence of postoperative nausea and vomiting in patients at a university hospital. Where are we today? Biomed Pap Med Fac Univ Palacky Olomouc Czech Repub 2010;154(1):69-76.

7. Kovac AL. Prevention and treatment of postoperative nausea and vomiting. Drugs 2000;59(2):213-43.

8. Gan TJ. Risk factors for postoperative nausea and vomiting. Anesth Analg 2006;102(6):1884-98.

9. Watcha MF, White PF. Postoperative nausea and vomiting. Its etiology, treatment, and prevention. Anesthesiology 1992;77(1):162-84.

10. Apfel CC, Läärä E, Koivuranta $\mathrm{M}$, et al. A simplified risk score for predicting postoperative nausea and vomiting: conclusions from cross-validations between two centers. Anesthesiology 1999;91(3):693-700. 
11. Naguib M, el Bakry AK, Khoshim MH, et al. Prophylactic antiemetic therapy with ondansetron, tropisetron, granisetron and metoclopramide in patients undergoing laparoscopic cholecystectomy: a randomized, doubleblind comparison with placebo. Can J Anaesth 1996; 43(3):226-31.

12. Gan TJ, Coop A, Philip BK. A randomized, double-blind study of granisetron plus dexamethasone versus ondansetron plus dexamethasone to prevent postoperative nausea and vomiting in patients undergoing abdominal hysterectomy. Anesth Analg 2005; 101(5):1323-9.

13. White PF, Tang J, Hamza MA, et al. The use of oral granisetron versus intravenous ondansetron for antiemetic prophylaxis in patients undergoing laparoscopic surgery: the effect on emetic symptoms and quality of recovery. Anesth Analg 2006;102(5):1387-93.

14. Spector JI, Lester EP, Chevlen EM, et al. A comparison of oral ondansetron and intravenous granisetron for the prevention of nausea and emesis associated with cisplatin-based chemotherapy. Oncologist 1998;3(6): 432-8.
15. Carmichael J, Keizer HJ, Cupissol D, et al. Use of granisetron in patients refractory to previous treatment with antiemetics. Anticancer Drugs 1998;9(5):381-5.

16. de Wit R, de Boer AC, vd Linden GHM, et al. Effective crossover to granisetron after failure to ondansetron, a randomized double blind study in patients failing ondansetron plus dexamethasone during the first 24 hours following highly emetogenic chemotherapy. Br J Cancer 2001;85(8):1099-101.

17. Hartsell T, Long D, Kirsch JR. The efficacy of postoperative ondansetron (zofran) orally disintegrating tablets for preventing nausea and vomiting after acoustic neuroma surgery. Anesth Analg 2005;101(5):1492-6.

18. Bhattacharya D, Banerjee A. Comparison of ondansetron and granisetron for prevention of nausea and vomiting following day care gynaecological laparoscopy. Indian J Anaesth 2003;47(4):279-82. 